\title{
EFFECTS OF SOCIAL NETWORK ON STUDENTS' PERFORMANCE: A WEB-BASED FORUM STUDY IN TAIWAN
}

\author{
Heng-Li Yang \\ Professor \\ Department of Management Information Systems \\ National Cheng-Chi University \\ 64 Section 2, Chihnan Road, \\ Mucha Dist., 116, \\ Taipei, Taiwan \\ Phone: 886-2-29387651 \\ Fax: 886-2-29393754 \\ yanh@mis.nccu.edu.tw \\ Jih-Hsin Tang \\ Phd Candidate \\ Department of Management Information Systems \\ National Cheng-Chi University \\ Faculty of Management Information Systems \\ Tak Ming College \\ 56 Section 1, Huan-Shan Rd., \\ Taipei, Taiwan \\ Phone: 886-2-26585801 \\ jefftang@mail.mis.takming.edu.tw
}

\begin{abstract}
This research investigates the effects of social networks on students' performance in online education which uses networking as an adjunct mode for enhancing traditional face-to-face education or distance education. Using data from a 40-student course on Advanced Management Information Systems (AMIS), we empirically tested how social networks (friendly, advising, and adversarial) related to students' performance. First, advising network variables are positively related to student performance both in the class and on the forum. Adversarial variables are negatively correlated with almost all students' performance. Second, advising and adversarial network variables are good determinants for overall academic performance; however, adversarial network variables are not influential on students' performance on the forum. Friendship network variables are not determinants of students' performance. Implications for the results are also discussed.
\end{abstract}

\section{KEYWORDS}

Learning Effectiveness, Social Network Analysis, Asynchronous Learning, Forum 


\section{INTRODUCTION}

The impact of the Internet on education is an important issue that has caught both educators' and practitioners' attention in recent years [1-4]. According to Harasim [5], three new modes of education delivery make online education distinctive. They are (1) adjunct mode: using networking to enhance traditional face-to-face education or distance education; (2) mixed mode: employing networking as a significant portion of a traditional classroom or distance course; (3) pure online mode: relying on networking as the primary teaching medium for the entire course or program. Among these three education delivery modes, the pure online mode has caught the most attention. Several successful cases or critical factors of pure online education have been reported [see especially 6,7 ].

One major concern of online education is whether the learning is effective. Many studies have been conducted to explore the effectiveness of Web-based distance learning or asynchronous learning $[8,9]$. Although most studies showed that the learning outcomes of distance learning or asynchronous learning are as effective as or more effective than those of traditional face-to-face teaching [10-13], the results were not conclusive since the learning materials and goals might exert significant influence on outcomes. For example, conceptual learning might be different from technique learning [4]. Negative effects such as decrease in group effectiveness, increase in time required to complete tasks, and decrease in member satisfaction were confirmed [14]. Students' feeling of isolation may also become an obstacle in pure online education [15]. The adjunct mode and the mixed mode of online education should be explored in more detail because these two modes of online education could possess the advantages of both pure online and traditional face-to-face teaching. Yet, few studies have been conducted to explore the adjunct mode of online education $[4,16,17]$. Little is known regarding the learning effectiveness of these forms of online learning.

Several recent studies demonstrated that asynchronous online interaction might provide learners flexibility, stimulate more innovative ideas, and facilitate learning. For example, Dietz-Uhler and BishipClark [18] found that face-to-face discussions preceded by Computer-mediated Communications (CMC) were perceived to be more enjoyable and could include a greater diversity of perspectives than the faceto-face discussions not preceded by CMC. Hammond [19] also argued that there is a particular educational value in a communicative approach to online discussions. Benbunan-Fich and Hiltz [20] found that groups working in an asynchronous network environment produced better and longer solutions to case studies, but were less satisfied with the interaction process. Picciano [21] found that students' online interactions were related to written assignments but not students' final grades. Thus, it would be interesting to investigate students' learning outcomes when online discussion forums are integrated into traditional classroom pedagogy, as in the adjunct mode of online education.

The importance of interpersonal interaction in learning is undoubted. Several learning theories put special emphasis on the effects of interpersonal interaction on learning outcomes [22]. For example, collaborative learning theory assumes that learning emerges through interactions of an individual with others. Online collaborative learning has also been explored and substantial interaction differences were found when compared with face-to-face collaborative behaviors [23]. Constructivism regards learning as a social process that takes place through communication with others. The learner actively constructs knowledge by formulating ideas into words, and these ideas are built upon reactions and responses of others. In other words, learning is not only active but also interactive [24]. From the perspectives of collaborative learning and constructivism, interpersonal interaction is one of the most important elements or processes of learning. As one of the most popular approaches for investigating human interactions, social network analysis is utilized in this study to contrast the social network effects on learner's performance between online and offline learning. 
The measurement of student performance is certainly open to many definitions. Depending upon the content of the course and the nature of the students, successful completion of a course, course withdrawals, grades, added knowledge, and skill building are some of the ways by which performance is measured, [21]. It is not the intention of this study to measure the students' perception of learning experiences, but rather to measure their credit achievements on the forum and in the class.

To address the issue of learning effectiveness of this adjunct mode of online education, it is better to design a field experiment comparing student performance among three modes of online education. Unfortunately, it is difficult to design the same experimental conditions for all three modes (i.e. the same subjects, the same learning time) in a manner that makes the comparisons sound and valid. Questions raised in this study are: (1) is an individual's position in a social network related to his or her performance online and offline? (2) what kind of social relations are linked with a student's academic performance?

The main purpose of this study is to explore the impact of interpersonal relationship networks on students' academic performance online and offline, and to find out the key human relationship determinants for students' performance.

\section{THE EFFECTS OF SOCIAL NETWORKS ON AN INDIVIDUAL'S PERFORMANCE}

There is a growing body of studies emphasizing that individuals are embedded in their societies. Thus, the related social structure, though sometimes invisible, is often associated with instrumental outcomes, including power [25], innovation [26], learning outcomes [27], and job performance [28]. Haythornthwaite [29] examined the distance learners' interactions in class and profiled students' roles and information exchange among distance learners' social networks. In a university course, Guldner and Stone-Winestock [30] empirically demonstrated that appropriate arrangement of groups according to each student's position in a social network might increase the student's learning satisfaction and academic performance.

The social network approach holds that the behavior of an individual is affected by the kinds of relations, or technical ties, and networks more than by the norms and attributes that an individual possesses. The social, informational, or material resources that two individuals exchange characterize their ties. In social network analysis, these resource exchanges are termed "relations." Some positive and negative relations are assumed to be related to an individual's performance. Researchers empirically demonstrated that friendship and advice relations were positively related to a student's academic performance and an employee's job performance. On the other hand, the effects of an adversarial network were negatively related to performance $[27,28]$. It seems worthwhile to investigate the effects of the three social networks on student performance online and offline.

Centrality is one of the most important concepts in social network analysis. The most common notion is that if a person is central in his or her group, he or she is the most popular individual in the group and gets the most attention. In early sociometry literature, centrality is called social status [31] and the sociometric concept of "star" refers to the same idea. Intuitively, a point is central if it is at the center of many connections; the simplest and most straightforward way to measure "point centrality" is by the degree of connectivity in the graph. Therefore, it is interesting to study the relationship between an individual's centrality in campus social networks (friendship, advising, and adversarial networks) and his or her performance in the classroom and in the forum. 


\section{A. Friendship Networks}

Friendship between two people can emerge only if and when their paths cross. They will have to 'meet' before they can 'mate.' They would be more likely to meet if they share, for example, the same living, school, or work environment, or if their social networks overlap [32]. Once two people meet, whether or not they decide to pursue a friendship depends on many additional factors. The structural context not only determines whether individuals meet, but also influences other important factors such as visibility and propinquity. Increased visibility and exposure increase the likelihood of becoming friends [33]. Therefore, a student who is central in a friendship network has more opportunities to access resources that may be important to successful academic performance. Perhaps most importantly, the existence of a positive social relationship is in itself [34] a resource for a student in coping with academic related stresses. Friendship networks often entail access to information and knowledge directly and indirectly, and the friendship network effect on student academic performance has been confirmed [27]. A student who is central in a friendship network has a greater chance of helping others and being helped; thus, he is likely to perform better in the traditional instructional setting. Likewise, those who are central in their friendship networks are likely to be popular in the Web-based forum, and the possibility of performing an excellent job in the forum is also higher. If a student performs a job in the forum well, he or she has a better chance to develop friendships with other students. Thus, the following hypotheses were formed.

\section{Hypothesis 1a. Individual centrality in a friendship network is positively associated with individual performance in the traditional instructional setting.}

\section{Hypothesis 1b. Individual centrality in a friendship network is positively associated with individual performance on the Web-based forum.}

\section{B. Advice Networks}

Advice networks consist of relations through which individuals share resources such as information, assistance, and guidance that are related to the completion of their work [28]. The advice network is more instrumental-oriented than is the friendship network (which is more social-oriented). Advice networks can be classified as instrumental ties rather than primary ties [35]. When a task is to be done, an individual can enhance his or her job by obtaining help from available advice networks. Thus, centrality in the advice network reflects an individual's involvement in exchanging resources in the process of problem solving. A student who is central in his advice network is capable of accumulating information, knowledge, and experiences about task-related problems, and thus is likely to perform better in the traditional classroom setting. Likewise, he is also more likely to perform well on the Web-based forum because he is expected to give advice to others, and sometimes give more high quality opinions.

Hypothesis 2a. Individual centrality in an advice network is positively associated with individual performance in the traditional instruction setting.

Hypothesis $2 \mathrm{~b}$. Individual centrality in an advice network is positively associated with individual performance on the Web-based forum. 


\section{Adversarial Networks}

Adversarial relations refer to those relations that may involve negative exchanges. Those kinds of relations cause emotional distress, anger, or indifference. They have been demonstrated empirically to be detrimental to student performance and satisfaction [27], and thus, are negatively related to work performance [28]. Adversarial relations may thwart information and knowledge exchange, and thus it is quite reasonable to infer that adversarial relations are negatively related to student performance. By the same token, if a student has an adversarial image on the forum, he or she has less of a chance to develop good relationships in the classroom, thereby undermining his or her chance of getting information or knowledge from others. Based on our earlier discussion, the following hypotheses are proposed:

\section{Hypothesis 3a. Individual centrality in an adversarial network is negatively associated with individual performance in the traditional instruction setting.}

\section{Hypothesis 3b. Individual centrality in an adversarial network is negatively associated with individual performance in the Web-based forum.}

\section{RESEARCH METHOD}

\section{A. Samples and Procedures}

Forty graduate students took a required course, "Advanced Management Information Systems (AMIS)", at National Cheng-Chi University, Taiwan. The three-credit course is a combination of traditional lecture, paper reading, text-book case and live case discussions. Case-based learning is widely used in business schools and makes discussion important in these learning environments. A Web-based forum was set up specifically for this course to stimulate students' in-depth discussions and to release the time constraint of the classroom discussion. Fourteen teams were formed: twelve teams consisted of three persons and the others had two. Each team had to write a live MIS case, present it in class, and develop discussion questions. Before each class, students had to submit answers to several pre-class questions, and they had to participate in the discussions in the forum after each class. The role of the online forum in this class was to supplement in-class discussions. Each week, the instructor provided some controversial topics to be discussed. One team, who wrote a live case, provided other questions and was responsible for writing the weekly summaries. Students were also free as web-board masters to call other students to discuss any case-related questions. The discussion questions might look like "is Taco Bell capable of selling foods on Internet? Why or why not?" or "could EZPEER, an Internet peer-to-peer MP3 exchange center, survive?" Some debates were zealous and interesting. At the end of the semester, a questionnaire was e-mailed to all students. Only one student turned in an incomplete questionnaire, leaving 39 usable samples. Of the 39 respondents, 13 were from females. One was a foreign student in her second year; the remaining were in their first semester. Most of them were unacquainted with one another before entering this program, and their social networks developed gradually during the semester - in class, after class, and in the forum.

\section{B. Measures}

The questionnaire was designed to measure the social network variables. It consisted of seven items to measure individual centrality in terms of advice, friendship, and adversarial dimensions. Students were asked to pick names from a list of all students. Following the work of Ibarra [26] and Sparrowe et al. [28], advice relations could be assessed by asking respondents three questions, such as "do you go to [name] for help or advice while you have pre-AMIS and post-AMIS questions?" Instead of using one item that is unreliable, three items were administered to acquire a more trustworthy measure of the advice network. Following the work of Baldwin and colleagues [27], friendship relations were measured by asking two 
questions: "Which of the following individuals will still be your friends after you go off campus?" "Whom will you invite if you have a celebration, such as a birthday party?" Similarly, the adversarial relations were measured by asking them two questions: "Which of the following individuals are difficult to keep a good relationship with?" "Who is difficult to get along with?" The questionnaire is provided in the Appendix.

Student academic performance included four components: live case, final exam, classroom performance, and forum performance. Classroom performance was measured by classroom presentation and participation in discussions. The forum performance was assessed based on posting quality and quantity. The posting quantity score was computed as follows: 11 postings was the minimum required; 0.05 points for each additional posting was given (up to a maximum of 3 points). Posting quality was subjectively judged by the instructor (the first researcher) according to criteria such as creativity, soundness, usefulness, and more. At the end of the semester, there was an election of "best performers in the forum," as voted by all students. The election results also gave the instructor an important quality reference.

\section{RESULTS}

\section{A. Common Factor Analysis}

Normalized in-degree centrality scores were adopted in this study since they are easier to comprehend [36]. In-degree centrality is a form of centrality that counts only relations with a focal individual reported by other members. In this study, the seven-item questionnaire assigned to each student seven normalized in-degree centrality scores which measured his or her prominence in terms of advice, friendship, and adversarial dimensions. In addition, factor analysis was adopted to analyze these network variables. The results are shown in Table 1. Three factors were extracted by the un-weighted least square method. Three factors explaining 84 percent of the variance in the network measures have eigen values greater than 1.0. The three advice network centrality items show high loadings (from 0.73 to 0.81 ) on the first factor, and the two adversarial centrality items show high loadings (greater than 0.85 ) on the second factor. However, the two friendship centrality items show inconsistent loadings on the first and third factors (from 0.37 to 0.79), which implies that the latent factor of friendship is not significantly different from that of the advice. Item 2 for measuring friendship "Whom will you invite if have a celebration, such as a birthday party?" was excluded from further analysis because few respondents in the study replied that they would ever hold a birthday party (this is probably because our activity example, a birthday party, is not a custom in Chinese culture, although we used the phrase, "such as"). In other words, this item is a little flawed, which might explain the inconsistency. Even though there are a few inconsistent factor loading patterns in Table 1, the results demonstrate convergent and discriminate validity for the network scale in this study. 
TABLE 1 Results of Factor Analysis on Network Variables

\begin{tabular}{|l|c|c|c|}
\hline \multirow{2}{*}{$\begin{array}{l}\text { Network } \\
\text { Variable }\end{array}$} & 1 & 2 & Factor \\
\cline { 2 - 4 } & & & 3 \\
\hline Advice 1 & 0.81 & 0.02 & -0.21 \\
\hline Advice 2 & 0.73 & -0.05 & -0.20 \\
\hline Advice 3 & 0.79 & 0.14 & -0.51 \\
\hline Friendship 1 & 0.60 & 0.11 & 0.79 \\
\hline Friendship 2 & 0.58 & 0.26 & 0.37 \\
\hline Adversarial 1 & -0.18 & 0.86 & -0.02 \\
\hline Adversarial 2 & -0.17 & 0.85 & -0.11 \\
\hline
\end{tabular}

\section{B. Relationship between Social Network Variables and Students' Academic Performance}

To make results more concise and understandable, three factors were extracted for further analysis. As shown in Table 2, Pearson correlations were computed between network factors and student performance in class, in Web-based forum, and in overall academic grades.

The results in Table 2 seem to support Hypotheses $1 \mathrm{a}$ and $1 \mathrm{~b}$ since significant relations exist between academic performance indicators and friendship factor coefficients. The results are slightly different from Baldwin, Bedell, and Johnson's findings [27]. In their study, centrality in friendship networks was found to be related only to team-based learning satisfaction, not with an individual's performance. Our results could be explained as follows. Friendship usually serves a psychological function of companionship. Centrality in friendship might give an individual a better chance of gaining access to information and knowledge, though he might not take advantage of it or be aware of it. However, some caution is needed in explaining the effects of the friendship. Centrality in friendship might be related to learning outcomes both in the classroom and on the forum, but its effects might be through some intervening variables such as learning motivation and emotion, or advice network centrality. By the same rationale, the most popular student in a class may not necessarily outperform others.

As shown in Table 2, Hypotheses $2 \mathrm{a}$ and $2 \mathrm{~b}$ are corroborated. Centrality in advice networks was related positively to scores in classroom participation and on the forum. That is to say, the individual, who was central in the advice network was expected to perform better in discussion, both in the classroom and in the Web-based forum. However, advice centrality was not significantly related to final exam score and case study performance. An individual's final exam grade is no doubt related to several variables such as effort, ability, and so on. Thus, the effect of advice centrality might be weakened by other uncontrolled factors in the current study. In addition, the case study performance was related more to team performance because the live case and its accompanying discussion questions were written and prepared by all team members.

The results in Table 2 partially support Hypotheses $3 \mathrm{a}$ and $3 \mathrm{~b}$. Centrality in an adversarial network was negatively related to all academic indicators. However, only final exam scores and overall grades were significantly related to adversarial centrality. These findings were not surprising since respondents' replies to the "adversarial items" were sparse, with an average of 1.49 "relations" on the first item and 
1.26 on the second. The sparse relations made adversarial centrality a less powerful index.

Summing up, all hypotheses are partially supported in this study. Friendship centrality and advice centrality were positively related to student performance both in the classroom and on the Web-based forum, and adversarial network centrality was negatively related to students' academic performance indicators, although some were insignificant.

Table 2 Basic Statistics and Correlations between Network Factors and Performance Variables

\begin{tabular}{|c|c|c|c|c|c|c|c|c|c|c|}
\hline & Mean & s.d. & 1 & 2 & 3 & 4 & 5 & 6 & 7 & 8 \\
\hline 1. Advice & -- & -- & 1.00 & & & & & & & \\
\hline 2. Adversarial & -- & -- & 0.00 & 1.00 & & & & & & \\
\hline 3. Friendship & -- & -- & $0.69^{* *}$ & 0.06 & 1.00 & & & & & \\
\hline 4.Overall Grade & 81.51 & 7.87 & $0.40^{*}$ & $-0.36^{*}$ & $0.46^{* *}$ & 1.00 & & & & \\
\hline 5.Case & 82.69 & 6.62 & 0.04 & -0.15 & 0.13 & $0.47 * *$ & 1.00 & & & \\
\hline 6.Class Participation & 171.45 & 7.16 & $0.40 *$ & -0.12 & $0.37 *$ & $0.84 * *$ & 0.29 & 1.00 & & \\
\hline 7.Final Exam & 62.531 & 13.13 & 0.07 & $-0.42 *$ & 0.29 & $0.78 * *$ & 0.25 & $0.53 * *$ & 1.00 & \\
\hline $\begin{array}{l}\text { 8. Forum Posting } \\
\text { Quality }\end{array}$ & 1.55 & 1.65 & $0.59^{* *}$ & -0.16 & $0.46^{*}$ & $0.66^{* *}$ & 0.02 & $0.63 * *$ & 0.20 & 1.00 \\
\hline $\begin{array}{l}\text { 9.Forum Posting } \\
\text { Quantity }\end{array}$ & 1.33 & 0.99 & $0.39 * *$ & -0.25 & $0.46^{*}$ & $0.60 * *$ & 0.11 & $0.49 * *$ & 0.23 & $0.71 * *$ \\
\hline
\end{tabular}

\section{Network factors on predicting academic performance}

As noted in the above discussions, friendship centrality, advice centrality and adversarial centrality were related to academic performance indicators. Hence, it would be interesting to study what were the best determinants of a student's class performance offline and online. In addition, were there any differences between the determinants?

Table 3 presents the results of regression analyses with an individual's overall grade as the dependent variable and three network structure variables as the independent variables. As shown in Table 3, advice network centrality was the best determinant of a student's grade, and adversarial centrality was another good predictor. These two network factors could explain 25 percent of the total variance. These results are comparable to findings by Sparrowe and colleagues [28]. In their study, advice network and "hindrance" network variables could explain 13 percent of the variance in in-role performance and 10 percent in extrarole performance, and 23 percent of the total variance.

It would be interesting to find the best determinant of students' performance on the forum. Tables 4 and 5 present the step-wise regression results with the dependent variables forum posting quantity (determined by the number of postings) and posting quality. As shown in the tables, the best determinant of a student's performance on the forum, both quantity and quality, was advice network. Advice network variables could explain 20 percent of the variance in posting-quantity performance, and 34 percent in postingquality performance. 
In comparison with the results in Table 3, adversarial network centrality was excluded in the prediction of student performance on the forum. A reasonable explanation is that the effects of adversarial network were weaker in the forum. With the distance in space and time, the effects of a negative relationship were not as influential as in the face-to-face settings. Another difference existed between forum posting performance on quality and quantity. The forum posting performance, measured by quality and quantity, could be determined to an extent by advice network variables. However, advice network accounted for more variance in posting quality than in posting quantity. These results could be attributed to the measurement itself. The quality of student performance in the discussion forum was evaluated subjectively by the course instructor, whereas the quantity of performance was computed objectively by the number of postings.

TABLE 3 Results of Regression Analysis for Network Centrality on Grade

\begin{tabular}{|l|c|c|c|c|c|}
\hline & $\begin{array}{c}\text { Partial } \\
\text { Coefficient }\end{array}$ & Standard Error. & $\begin{array}{c}\text { Standardized } \\
\text { Coefficient }\end{array}$ & $\mathrm{t}$ & $\begin{array}{c}\text { Significant } \\
\text { Level }\end{array}$ \\
\hline $\begin{array}{l}\text { (Constant) } \\
\begin{array}{l}\text { Advice } \\
\text { Network }\end{array}\end{array}$ & 81.51 & 1.09 & & 74.47 & 0.00 \\
\hline $\begin{array}{l}\text { Adversarial } \\
\text { Network }\end{array}$ & -2.65 & 1.14 & 0.44 & 3.10 & 0.00 \\
\hline $\begin{array}{l}\text { Overall } \\
\text { adjusted R }\end{array}$ & 0.25 & & -0.31 & -2.23 & 0.03 \\
\hline Overall F & $7.21^{* *}$ & & & & \\
\hline
\end{tabular}

$* * p<.01$

TABLE 4 Results of Regression Analysis for Network Centrality on Posting Quantity

\begin{tabular}{|c|c|c|c|c|c|}
\hline & $\begin{array}{c}\text { Partial } \\
\text { Coefficient }\end{array}$ & Standard Error. & $\begin{array}{c}\text { Standardized } \\
\text { Coefficient }\end{array}$ & $\mathrm{t}$ & $\begin{array}{c}\text { Significant } \\
\text { Level }\end{array}$ \\
\hline Constant & 1.33 & 0.14 & & 9.36 & 0.000 \\
\hline $\begin{array}{c}\text { Advice } \\
\text { Network }\end{array}$ & 0.48 & 0.15 & 0.47 & 3.22 & 0.003 \\
\hline $\begin{array}{c}\text { Overall } \\
\text { adjusted } \mathrm{R}^{2}\end{array}$ & 0.20 & & & & 0.000 \\
\hline $\begin{array}{c}\text { Overall } \mathrm{F} \\
* 01\end{array}$ & $10.39 * *$ & & & & 0.003 \\
\hline
\end{tabular}


TABLE 5 Results of Regression Analysis for Network Centrality Performance on Posting Quality

\begin{tabular}{|c|c|c|c|c|c|}
\hline & $\begin{array}{c}\text { Partial } \\
\text { Coefficient }\end{array}$ & Standard Error. & $\begin{array}{c}\text { Standardized } \\
\text { Coefficient }\end{array}$ & $\mathrm{t}$ & $\begin{array}{c}\text { Significant } \\
\text { Level }\end{array}$ \\
\hline Constant & 1.55 & 0.21 & & 7.21 & 0.000 \\
\hline $\begin{array}{c}\text { Advice } \\
\text { Network }\end{array}$ & 1.01 & 0.22 & 0.60 & 4.54 & 0.000 \\
\hline $\begin{array}{c}\text { Overall } \\
\text { adjusted } \mathrm{R}^{2}\end{array}$ & 0.34 & & & & 0.000 \\
\hline Overall F & $20.64 * * *$ & & & & \\
$* * 01$ & & & &
\end{tabular}

\section{DISCUSSION}

It is interesting that while e-learning, distance learning, and asynchronous learning have a great impact on education systems globally, the traditional classroom pedagogy has not been replaced by these new learning modes. Instead, more and more teachers have explored Web-based applications by providing discussion forums as extension to, rather than replacement for, "conventional" teaching. One plausible reason is as follows. As an important component of learning, interpersonal relationship may foster the exchange of information and knowledge, or may enhance learning motivations. Such a role could not be easily replaced by only computer technology. Even for pure online learning, exchange of information and social support with others may enhance student performance and satisfaction [21,37]. For example, Rafaeli and Sudweeks [38] found that online conversations are more social in nature and that interactive messages seem to be humorous, contain more self-disclosure, display a higher preference for agreement, and contain many first-person plural pronouns. This indicates that interpersonal interaction plays an important role in online learning.

The relationship between network structure and learning has been investigated since the inception of sociometry decades ago [39]. However, few researchers have examined the effects of network structure on learning achievement or job performance [40]. This can be explained by the fact that "complex network indices" were developed in late $70 \mathrm{~s}$ to $90 \mathrm{~s}$, and the calculation of these indices requires the use of computers. The explosive use of the Internet has made CMC a hot research topic, and modern social network analysis is widely known and exploited nowadays [41]. The empirical study demonstrated that network structure is related to student performance both in the classroom and on the Web-based forum. The relationship between network structure and student performance might be reciprocal, that is, there might be no implicit causal relationship behind this relationship. This study further demonstrated that the three types of network, friendship, advice and adversarial, might be related to student performance both in the class and on the discussion forum.

How can the results be explained? Network effects on student performance were confirmed in previous studies [27, 28]. However, this study showed that network effects on student performance exist for both on-line and off-line learning. Most students in the study did not were not acquainted before joining this program; and the "relationships" developed during the semester. The acquaintances among students began in the face-to-face classroom. However, the 24-hour forum fostered their familiarity. One team member wrote in the private notepad for her team (which could be accessed by only themselves and the 
instructor); "Because of the forum connection, we have become very intimate, so close, even closer than our families, lovers, and others."

The social network formed by these students was different from that of distance learners (as in Haythornthwaite's study) since the latter developed their relationships mainly through online interactions. Actually, there were three sessions during which the students could develop their networks - in the AMIS class, before and after the class, and in the forum. Since the class period was only three hours per week, we might conjecture that most of the friendship and adversarial networks developed after the class. In the AMIS class, most of the discussions were one (lecturer) to many (students). Therefore, although students were motivated to show their knowledge during the class, the advice network could not develop. However, on the forum, the discussions were many to many. Everyone was free to express an opinion and knew the teacher was watching to see how valuable were the opinions or information they provided to all the members of the forum. The advice network could naturally evolve over time. This might explain why the advice network centrality is the best determinant for explaining performance variance.

Because the students' social network developed before the final learning outcomes, we assert the tentative proposition that a social network exerts its effect on learning processes and effectiveness even though there is no true causal relationship has ever been established.

Furthermore, if the advice network has determining effects on students' academic performance, then what are the implications for instruction design? A Web-based forum may offer an excellent medium for students to communicate with each other, a chance to express themselves [42], and an environment with fewer problems, such as those connected with shyness. If knowledge is mainly constructed through interaction among students and between students and their instructor, then interactions among students should be strongly encouraged. Then, a Web-based forum may provide students a field where they can freely discuss, ask questions, give opinions, and learn after class. There are several methods that can enhance online learners' interactions, such as provision of a controversial topic for debate or structuring a controversy [43]. Some hot debates (such as Microsoft's privacy invasion, fast-food selling skills, and others) occurred in this study during some weeks. Stimulating students' interaction and providing appropriate feedback may become a teacher's main tasks.

Future work should focus on the design and management of learning structures in a way that promotes network development. For example, it is important to know what should be included in a class discussion and what should be left or extended to the forum. The future challenge will be how to design different instruction and discussion sessions online and offline in order to fully exploit the advantages of students' social networks.

\section{A. Limitations}

This study has several potential limitations. The first concerns the validity of performance measures. Several activities were required for students in the course: live-case preparation, discussions in the classroom and on the forum, and final examination. Yet, there were no objective measurement scales for performance in all these activities. Even though some criteria were set up, such as the "best performers on the forum" elected by all respondents, to crosscheck the validity of performance measurement on the forum, there could exist bias in an individual's ratings.

Second, our regression analyses imply that network structure phenomena precede an individual's performance. However, the relationship between individual performance and network structure might be reciprocal. For example, it is possible that when one performs well in the class and on the forum, one's popularity will increase in the friendship and advice networks. This needs to be confirmed by further investigation. 
Third, only one class participated in this study and the subjects were graduate students in a university in Taipei. Thus, the representativeness of the sample is questionable; caution must be exercised in generalizing the results.

\section{APPENDIX}

\section{Questionnaires to measure network variables:}

Advice Network:

Advice 1:

"Do you go to [name] for help or advice when you have pre-AMIS or post-AMIS questions?"

Advice 2:

"Do you go to [name] for help or advice when you have general AMIS questions?"

Advice 3:

"Do you go to [name] for help or advice when you have live-case questions?"

Friendship Network:

Friendship 1:

"Which of the following individuals [name] will be still your friends after you go off campus?"

Friendship 2:

"Who [name] will you invite if you have a celebration, such as a birthday party?"

Adversarial Network:

Adversarial 1:

"With which of the following individuals [name] is it difficult to maintain a good relationship?"

Adversarial 2:

"Who [name] is difficult to get along with?"

\section{ACKNOWLEDGMENT}

This research is sponsored by National Science Council, Taiwan, Project \# NSC 91-2522-H-004-003.

The author also wishes to thank Editor-in-Chief, Professor John Bourne and anonymous reviewers for their helpful suggestions.

\section{ABOUT THE AUTHORS}

Heng-Li Yang is a professor in the Department of Management Information Systems, National ChengChi University. His research interests include data and knowledge engineering, database and knowledgebased systems, software engineering, information management in organizations, privacy issues, technology impacts on organizations, electronic commerce and empirical studies in MIS. His articles have appeared in international journals such as Information \& Management, Journal Processing and Management, Cybernetics and Systems, Data and Knowledge Engineering, Expert Systems with Applications, Journal of Information Science and Engineering, and Industrial Management and Data Systems. 
Jih-Hsin Tang holds a Ph.D. from National Cheng-Chi University. He currently is an instructor in the Department of Management Information Systems, Tak-Ming College. His research interests include requirement elicitation methods for Web-based Information systems and group dynamics of ISD teams. His articles have appeared in international journals such as Information Management and Computer Security, Industrial Management \& Data Systems, and Journal of Asynchronous Learning Networks.

\section{REFERENCES}

1. Janicki, T. and Liegle, J. O. Development and evaluation of a framework for creating web-based learning modules: a pedagogical and systems perspective. Journal of Asynchronous Learning Networks, 2001. 5(1), This paper is online at http://www.sloan-c.org/publications/jaln/v5n1/v5n1 janicki.asp

2. Tolmie, A. and Boyle, J. Factors influencing the success of computer mediated communication (CMC) environments in university teaching: a review and case study. Computers and Education, 34: 119-140, 2000.

3. Rossman, M. H. Successful online teaching using an asynchronous learner discussion forum. Journal of Asynchronous Learning Networks, 3(2): 91-97, 1999. This paper is online at http://www.sloan-c.org/publications/jaln/v3n2/v3n2 rossman.asp

4. Parker, D. and Gemino, A. Inside online learning: comparing conceptual and technique learning performance in place-based and ALN formats. Journal of Asynchronous Learning Networks, 5(2): 64-74, 2001. This paper is online at http://www.sloan-c.org/publications/jaln/v5n2/v5n2 parkergemino.asp

5. Harasim, L. Shift happens: online education as a new paradigm in learning. Internet and Higher Education, 3: 41-61, 2000.

6. McGorry, S. Y. Online, but on target? Internet-based MBA courses: a case study. Internet and Higher Education, 5: 167-175, 2002.

7. Lieblein, E. Critical factors for successful delivery of online programs. Internet and Higher Education, 3: 161-174, 2000.

8. Alavi, M., Yoo, Y. and Vogel, D. R. Using information technology to add value to management education. Academy of Management Journal, 40(6): 1310-1333, 1997.

9. Webster, J. and Hackley, P. Teaching effectiveness in technology-mediated distance learning. Academy of Management Journal, 40(6): 1282-1309, 1997.

10. Motiwalla, L. and Tello, S. Distance learning on the Internet: an exploratory study. Internet and Higher Education, 2(4): 253-264, 2001.

11. Wilson, T. and Whitelock, D. What are the perceived benefits of participating in a computermediated communication (CMC) environment for distance learning computer science students? Computers and Education, 30(3/4): 259-269, 1998.

12. Yakimovicz, A. D. and Murphy, K. L. Constructivism and collaboration on the Internet: case study of a graduate class experience. Computers and Education, 24(3): 203-209, 1995.

13. Hiltz, S. R. and Turoff, M. What makes learning effective? Communications of ACM, 49(4): 5659, 2002.

14. Baltes, B. B., Dickson, M. W., Sherman, M., Bauer, C. C. and LaGanke, J. S. Computermediated communication and group decision making: a meta-analysis. Organizational Behavior and Human Decision Processes, 87(1): 156-179, 2002.

15. Ricketts, J., Wolfe, F. H., Norvelle, E. and Carpenter, E. H. Asynchronous distributed education-a review and case study. Social Science Computer Review, 18(2): 132-146, 2000.

16. Guzdial, M. and Turns, J. Effective discussion through a computer-mediated anchored forum. Journal of the Learning Sciences, 9(4): 437-469, 2000.

17. Thomas, M. J. W. Learning within incoherent structures: the space of online discussion forums. Journal of Computer Assisted Learning, 18: 351-366, 2002. 
18. Dietz-Uhler, B. and Bishop-Clark, C. The use of computer-mediated communication to enhance subsequent fact-to-face discussions. Computers in Human Behavior, 17: 269-283, 2001.

19. Hammond, M. Communications within on-line forums: the opportunities, the constraints and the value of a communicative approach. Computers and Education, 35: 251-262, 2000.

20. Benbunan-Fich, R. and Hiltz, S. R. Educational applications of CMCS: solving case studies through asynchronous learning networks. Journal of Computer-Mediated Communications, 4(3), 1999. This paper is online at http://www.ascusc.org/jcmc/vol4/issue3/benbunan-fich.html

21. Picciano, A. G. Beyond student perceptions: issues of interaction, presence, and performance in an online course. Journal of Asynchronous Learning Networks, 6(1): 21-40, 2002. This paper is online at http://www.sloan-c.org/publications/jaln/v6n1/v6n1_picciano.asp.

22. Lin, B. and Hsieh, C. T. Web-based teaching and learner control: a research review. Computers and Education, 37: 377-386, 2001.

23. Curtis, D. D. and Lawson, M. J. Exploring collaborative online learning. Journal of Asynchronous Learning Networks, 5(1): 21-34, 2001. This paper is online at http://www.sloan-c.org/publications/jaln/v5n1/v5n1 curtis.asp

24. Hiltz, S. R., Coppola, N., Rotter, N., and Turoff, M. Measuring the importance of collaborative learning for the effectiveness of ALN: a multi-measure, multi-method approach. Journal of Asynchronous Learning Networks, 4(2). This paper is online at http://www.sloan-c.org/publications/jaln/v4n2/v4n2 hiltz.asp.

25. Brass, D. J. Being in the right place: a structural analysis of individual influence in an organization. Administrative Science Quarterly, 29: 518-539, 1984.

26. Ibarra, H. Network centrality, power and innovation involvement: determinants of technical and administrative roles. Academy of Management Journal, 36: 471-501, 1993.

27. Baldwin, T. T., Bedell, M. D. and Johnson, J. L. The social fabric of a team-based M.B.A. program: network effects on student satisfaction and performance. Academy of Management Journal, 40(6): 1369-1397, 1997.

28. Sparrowe, R. T., Liden, R. C. and Kraimer, M. L. Social networks and the performance of individuals and groups. Academy of Management Journal, 44(2): 316-325, 2001.

29. Haythornthwaite, C. A Social Network Study of the Growth of Community Among Distance Learners. in Internet Research and Information for Social Scientists Conference, Bristol, UK. 1998.

30. Guldner, C. E. and Stone-Winestock, P. The use of sociometry in teaching at the university level. Journal of Group Psychotherapy, Psychodrama \& Sociometry, 47(4): 177-186, 1995.

31. Wasserman, S. and Faust, K. Social Network Analysis. 1994: Cambridge.

32. Fehr, B. Friendship processes. 1996, Thousand Oaks, California: Sage.

33. Zeggelink, E., Stokman, F., Van Duijn, M., and Wasseur, F. Evolution of sociology freshmen into a friendship network. Working Paper, 2001.

34. Ibarra, H. Race, opportunity, and diversity of social circles in managerial networks. Academy of Management Journal, 38: 673-703, 1995.

35. Lincoln, J. and Miller, J. Work and friendship ties in organizations: a comparative analysis of relational networks. Administrative Science Quarterly, 24: 181-199, 1979

36. Borgatti, S., Everett, M.G. and L.C. Freeman, UCINET 5.0 Version 1.00. 1999, Natick: Analytic Technologies.

37. Hiltz, S. R. and Wellman, B. Asynchronous learning networks as a virtual class. Communications of $A C M, 40(9)$ : 44-50, 1997.

38. Rafaeli, S. and Sudweeks, F. Networked interactivity. Journal of Computer-Mediated Communications, 2(4), 1997. This paper is online at http://www.ascusc.org/jcmc/vol2/issue4/rafaeli.sudweeks.html.

39. Evans, K. M. Sociometry and Education. 1962, New York: The Humanities Press.

40. Lucius, R.H. and Kunert, K.W. Using sociometry to predict team performance in the work place. Journal of Psychology, 131(1): 21-32, 1997. 
41. Garton, L., Haythornthwaite, C. and Wellman, B. Studying online social networks, in Doing Internet Research, Steve Jones (eds.), Sage: CA, 1999.

42. Seale, J. and Cann, A. J. Reflection on-line or off-line: the role of learning technologies in encouraging students to reflect. Computers and Education, 34: 309-320, 2000.

43. Clark, J. Stimulating collaboration and discussion learning environments. Internet and Higher Education, 4: 119-124, 2001. 